\title{
The Medicinal Importance of Annona squamosa fruits
}

\author{
Tahereh Hosseinabadi* ${ }^{*}$ \\ Department of Pharmacognosy and Pharmaceutical Biotechnology, School of Pharmacy, Shahid Beheshti \\ University of Medical Sciences, Tehran, Iran
}

\begin{abstract}
Annona squamosa is a medicinal plant with edible fruits and is commonly known as the sugar apple. This plant belongs to the Annonaceae family and has been used as a traditional medicine for many years with benefits for patients with various diseases. ${ }^{1,2}$ However, there is little information regarding the medicinal basis of this plant and the action of its pods and seed oil. Recently, Adesanwo et al. ${ }^{3}$ investigated the chemical constituents and anti-microbial activities of the fruits pods and seed oil extracts, as well as the antioxidant activity of seed oil. GC-MS analysis identified several potentially bioactive compounds, including numerous types of fatty acids and fatty acid esters. These results support previous observations regarding the presence of unsaturated fatty acids and acetogenins in seed oil. ${ }^{4}$ Functional studies have also revealed that the purified fruit pod extracts and seed oil of A. squamosa exhibit broad-spectrum antibacterial properties. Interestingly, previous antibacterial activities previously reported from $A$. squamosa leave extracts on some bacterial strains. ${ }^{5-7}$ In addition, the seed oil extracts of $A$. squamosa have been found to exhibit potent antioxidant activity, extending previous reports on seed, ${ }^{8}$ leave, ${ }^{5,9}$ and fruit pulp ${ }^{10}$ extracts. Such novel findings may help in understanding the pharmacological actions of A. squamosa and potentially open a new direction for further investigations.
\end{abstract}

Previous studies have shown that various chemical compounds, such as alkaloids, carbohydrates, tannins, phenolic compounds, isomeric hydroxyl ketones, cyclopeptides and acetogenins can be found in different parts of the A. squamosal plant. ${ }^{11,12}$ GC-MS analysis of $A$. squamosa fruit pod extracts has recently shown that 9,10-dehydro-isolongifolene, androsterone and spathulenol are major compounds found in the plant. These results extend previous reports as spathulenol has been reported to be present in fruit pulp extracts and essential oil. ${ }^{13,14}$ Furthermore, the determination of the chemical parameters of $A$. squamosa seed oil, including iodine, saponification, acid and peroxide values, as well as total phenol content is valuable for nutritional, industrial and medicinal utilization. In addition, the phenolic content of $A$. squamosa is associated with its anti-bacterial and antioxidant activity. 5,15

It is still unclear whether the human body can digest $A$. squamo$s a$ to generate such chemical molecules in vivo and which chemical components have beneficial biological effects in vivo. Therefore,

\footnotetext{
Abbreviations: GC-MS, gas chromatography-mass spectrometry.

Received: December 03, 2020; Revised: December 27, 2020; Accepted: January 04, 2021

${ }^{*}$ Correspondence to: Tahereh Hosseinabadi, Department of Pharmacognosy and Pharmaceutical Biotechnology, School of Pharmacy, Shahid Beheshti University of Medical Sciences, Tehran, Iran. ORCID: https://orcid.org/0000-0003-3127-0233. Tel: +98-2188665694, Fax:+98-21-88665250,E-mail: hosseinabadi.t@gmail.com; t.hosseinabadi@ sbmu.ac.ir

How to cite this article: Hosseinabadi T. The Medicinal Importance of Annona squamosa fruits. J Explor Res Pharmacol 2020;000(000):000-000. doi: 10.14218/JERP. 2020.00039 .
}

further phytochemical evaluations of $A$. squamosa pods (including more polar fractions) and seed oil with different extraction and chromatography methods are necessary to identify specific compounds with potent biological activities. Given that natural products play a special role in pharmacotherapy, the findings from this work may help develop new medicinal therapies for clinical applications.

\section{Acknowledgments}

None.

Funding

None.

\section{Conflict of interest}

There is no conflict of interest.

\section{References}

[1] Bhattacharya A, Chakraverty R. The pharmacological properties of Annona squamosa Linn: a review. Int J Pharm Eng 2016;4(2):692-699.

[2] Ma C, Chen Y, Chen J, Li X, Chen Y. A Review on Annona squamosa L.: Phytochemicals and Biological Activities. Am J Chin Med 2017;45(5): 933-964. doi:10.1142/S0192415X17500501.

[3] Adesanwo JK, Akinloye AA, Otemuyiwa IO, Akinpelu DA. Chemical Characteristics and Biological Activities of Annona squamosa Fruit Pod and Seed Extracts. J Explor Res Pharmacol 2020. doi:10.14218/ JERP.2020.00019.

[4] Chen Y, Chen Y, Shi Y, Ma C, Wang X, Li Y, et al. Antitumor activity of Annona squamosa seed oil. J Ethnopharmacol 2016;193:362-367. doi:10.1016/j.jep.2016.08.036.

[5] El-Chaghaby GA, Ahmad AF, Ramis ES. Evaluation of the antioxidant and antibacterial properties of various solvents extracts of Annona squamosa L. leaves. Arabian J Chem 2014;7(2):227-233. doi:10.1016/ j.arabjc.2011.06.019.

[6] Patel JD, Kumar V. Annona squamosa L.: Phytochemical Analysis and Antimicrobial Screening. J Pharm Res 2008;1(1):34-38.

[7] Neethu Simon K, Santhoshkumar R, Neethu SK. Phytochemical analysis and antimicrobial activities of Annona squamosa (L) leaf extracts. J Pharmacogn Phytochem 2016;5(4):128-131.

[8] Kothari V, Seshadri S. Antioxidant activity of seed extracts of Annona squamosa and Carica papaya. Nutr Food Sci 2010;40(4):403-408. doi:10.1108/00346651011062050.

[9] Kalidindi N, Thimmaiah NV, Jagadeesh NV, Nandeep R, Swetha S, Kalidindi B. Antifungal and antioxidant activities of organic and aqueous extracts of Annona squamosa Linn. leaves. J Food Drug Anal 
J Explor Res Pharmacol

2015;23(4):795-802. doi:10.1016/j.jfda.2015.04.012.

[10] Nandhakumar E, Indumathi P. In vitro antioxidant activities of methanol and aqueous extract of Annona squamosa (L.) fruit pulp. J Acupunct Meridian Stud 2013;6(3):142-148. doi:10.1016/j.jams.2012.09.002.

[11] Pandey N, Barve D. Phytochemical and pharmacological review on Annona squamosa Linn. Int J Res Pharm Biomed Sci 2011;2(4):14041412.

[12] Singh $Y$, Bhatnagar $P$, Thakur N. A review on insight of immense nutraceutical and medicinal potential of custard apple (Annona squamosa Linn.). Int J Chem Stud 2019;7(2):1237-1245.

[13] Thang TD, Dai DN, Hoi TM, Ogunwande IA. Study on the volatile oil
Hosseinabadi T. Importance of Annona squamosa fruits

contents of Annona glabra L., Annona squamosa L., Annona muricata L. and Annona reticulata L., from Vietnam. Nat Prod Res 2013;27(13): 1232-1236. doi:10.1080/14786419.2012.724413.

[14] Madhumitha G, Rajakumar G, Roopan SM, Rahuman AA, Priya KM, Saral AM, et al. Acaricidal, insecticidal, and larvicidal efficacy of fruit peel aqueous extract of Annona squamosa and its compounds against blood-feeding parasites. Parasitol Res 2012;111(5):21892199. doi:10.1007/s00436-011-2671-2.

[15] Tomar RS, Sisodia SS. Estimation of phenolic content, total flavonoids and in-vitro antioxidant activity of Annona squamosa Linn. and Bougainvillea glabra Choisy. J Global Pharma Technol 2013;3(5):11-14. 